\title{
Crônicas e cartas como laboratório multidisciplinar: a infância como tópos e o esboço de um éthos da província no Modernismo brasileiro
}

[ Articles and letters as a multidisciplinary laboratory: the childhood as a tópos and the outline of an éthos of the province in Brazilian Modernism

\section{Silvana Moreli Vicente Dias ${ }^{\mathrm{I}}$}

RESUMO - Pretende-se, aqui, discutir como a “infância" é dimensionada como tópos literário e se entrelaça com as perspectivas provinciana e brasileira a partir da correspondência pessoal e da obra publicada de escritores regionalista-modernistas nordestinos, tais como Gilberto Freyre, Jorge de Lima, José Lins do Rego e Manuel Bandeira. Arquivos da vida privada abrangem documentos plurais e heterogêneos, em meio aos quais as cartas ocupam espaço privilegiado como centro irradiador de relações intertextuais amplas. Veremos, assim, dispositivos afetivos e intelectuais na construção de imagens contraditórias da infância, da família e da província, sedimentadas a partir de um diálogo tenso, por exemplo, entre rural e urbano, público e privado, província e metrópole, tradição e vanguarda. PALAVRAS-CHAVE - Epistolografia moderna; Gilberto Freyre; Jorge de Lima; José Lins do Rego; Manuel Bandeira. • ABSTRACT . The objective of this essay is to discuss how the childhood becomes a literary tópos that relates to the provincial and the Brazilian perspectives taking as a basis of analysis the personal correspondence and the published work of some modernist-regionalist North-eastern writers, such as Gilberto Freyre, Jorge de Lima, José Lins do Rego, and Manuel Bandeira. Private archives can include diverse and plural documents, among which the letters of writers, intellectuals and artists occupy privileged space as radiating centre of broad intertextual relations. We will see, therefore, affective and intellectual devices in the construction of contradictory images of the childhood, the family and the province, regimented by a tense dialogue, for example, between rural and urban, public and private, province and metropolis, tradition and avant-garde. • KEYWORDS - Modern epistolography; Gilberto Freyre; Jorge de Lima; José Lins do Rego; Manuel Bandeira.

Recebido em 24 de maio de 2017

Aprovado em 7 de agosto de $20 I 7$

DIAS, Silvana Moreli Vicente. Crônicas e cartas como laboratório multidisciplinar: a infância como tópos e o esboço de um éthos da província no Modernismo brasileiro. Revista do Instituto de Estudos Brasileiros, Brasil, n. 67, p. 204-220, ago. 2017.

DOI: http://dx.doi.org/Io.II6o6/issn.2316-90IX.voi67p204-220

I Universidade Veiga de Almeida (UVA, Rio de Janeiro, RJ, Brasil). 
O decênio de I920 foi um marco para o adensamento do projeto intelectual de Gilberto Freyre. Ensaísta brasileiro de maior projeção internacional no século XX, autor de alguns dos pilares da interpretação do Brasil, como Casa-grande er senzala (I933) e Sobrados e mucambos (I936), sua obra continua a instigar. Porém, seu percurso de formação, complexo, contraditório e inovador em muitos aspectos, ainda pede tanto um cuidadoso trabalho de arqueologia em busca de textos fundamentais (de modo a perfazer sua opera omnia), quanto um esforço hermenêutico que o posicione junto às principais linhas de força do movimento moderno no Brasil, frequentemente representadas pela ruptura vanguardista capitaneada pelos participantes da Semana de Arte Moderna de I922, de um lado, e pelo projeto nacionalista de Mário de Andrade, de outro. Este artigo pretende palmilhar um universo de textos normalmente tidos como marginais, como cartas e crônicas, postos à sombra da obra canônica de autores, quer sejam estes prestigiados ou não. Desse modo, cartas e crônicas de Gilberto Freyre e seus amigos regionalista-modernistas, muitas delas inéditas ou nunca reunidas em livro, podem oferecer a base para se compreenderem aspectos da dinâmica de determinada produção literária, artística e intelectual do Modernismo, em grupos espalhados para além dos centros econômicos e políticos do país na época, como Rio de Janeiro e São Paulo.

O eixo a guiar este estudo é delineado pela própria expectativa dispersa nesses discursos epistolares e cronísticos no sentido de se edificarem figurações de uma "brasilidade autêntica" - delineada pelos autores como não postiça, não estática, não acrítica, não arremedo das vanguardas europeias - que também contemplasse uma leitura original, à época, da formação do Brasil moderno. Obviamente não se quer encobrir o caráter ideológico desse projeto, nem afirmar anacronicamente a 
possibilidade de se delimitar um tal éthos ${ }^{2}$. De outro modo, revisitar esses textos com olhar atento às suas especificidades seria uma maneira de se compreenderem singularidades processuais desses discursos cuidadosamente arquitetados, e muitas vezes paradoxalmente alinhavados, num determinado momento de nossa história. Com importantes reverberações até os dias de hoje, esses textos procuram estabelecer uma relação - em via de mão dupla - entre constatação inferida e projeção utópica das bases simbólicas de um país e de uma sociedade que se lançava na aventura da modernização. Assim sendo, muito embora seja indiscutível que, sobretudo nos estudos dedicados a Gilberto Freyre3, temos à disposição um volume crítico considerável, o objetivo, neste artigo, é - em perspectiva filológica, genética e crítica rastrear os meandros dos discursos que se formam, se entrecruzam, se projetam e se sedimentam, com fisionomia própria, em textos efetivamente inseridos no universo da arte e da cultura brasileira.

É possível dizer que a crítica já reconheceu uma espécie de continuum relativamente coerente do pensamento de Freyre retraçado a partir sobretudo de seu primeiro livro, Casa-grande er senzala, de I933, mas pouco ou insuficientemente considera a produção do decênio de I920 até I933, constituída em estreito diálogo com as vanguardas históricas e com projetos de modernização que reelaboram esteticamente elementos da cultura popular e da língua brasileira, dentre outros escopos que materializam processos singulares da produção literária, artística e cultural do país. Nesse sentido, Gilda de Mello e Souza, por exemplo, destaca convergências notórias entre Freyre e Mário de Andrade ao refletirem sobre a

2 Com relação à riqueza das acepções que conceitos como "província" e "provinciano" adquirem nos anos I920, dialogando com a concepção de um éthos da mistura tal como definido pelo próprio Gilberto Freyre, cf.: DIAS, Silvana Moreli Vicente. Perfis da província e máscaras da modernidade: uma leitura da correspondência de Gilberto Freyre com Manuel Bandeira, José Lins do Rego e Rodrigo Melo Franco de Andrade. Letras de Hoje, n. 49, n. 2, 20I4; DIAS, Silvana Moreli Vicente. Cartas provincianas: correspondência entre Gilberto Freyre e Manuel Bandeira. São Paulo: Global, 20I7; OLIVEIRA, Lucia Lippi. Gilberto Freyre e a valorização da província. Sociedade e Estado, v. 26, n. I, Brasília, jan.-abr. 20 II.

3 A trajetória multifacetada, polêmica e inovadora de Gilberto Freyre foi objeto de importantes estudos críticos; restaria, portanto, imparcial qualquer tentativa de tecer panoramas. Para o leitor que queira se iniciar na obra de Freyre, recomenda-se: CANDIDO, Antonio. Gilberto Freyre crítico literário. In: AMADO, Gilberto et al. Gilberto Freyre: sua ciência, sua filosofia, sua arte. Rio de Janeiro: J. Olympio, I962 (para quem a prosa do autor é marcada por uma "ambiguidade dinâmica"); LIMA, Luiz Costa. A versão solar do patriarcalismo: Casa-grande er senzala. In: A aguarrás do tempo: estudos sobre a narrativa. Rio de Janeiro: Rocco, I989 (que destaca uma flutuação conceitual entre determinação racial, climática, cultural e econômica em Casa-grande er senzala, aproximando-a da oralidade); ARAÚJO, Ricardo Benzaquen de. Guerra e paz: Casa-grande e senzala e a obra de Gilberto Freyre nos anos 30. Rio de Janeiro: Ed. 34, I994 (que revisita exemplarmente os "antagonismos em equilíbrio" no interior da obra de Freyre dos anos I930, inclusive destacando a qualidade ensaística de sua prosa); BASTOS, Elide Rugai. As criaturas de Prometeu: Gilberto Freyre e a formação da sociedade brasileira. São Paulo: Global/Fundação Gilberto Freyre, 2006 (que observa, na dialética entre decadência e sobrevivência, como antagonismos que poderiam ser irreconciliáveis se estabilizam na cultura patriarcal); PALLARES-BURKE, Maria Lúcia. Gilberto Freyre: um vitoriano dos trópicos. São Paulo: Ed. Unesp, 2005 (a qual percorre as influências antagônicas, sobretudo britânicas, na formação de Freyre). 
obra de Cícero Dias, conexões de dois "chefes-de-fila" em plena década de r920: "É o momento em que ambos pensam o Brasil moderno sem perder o contato com a cultura popular e a contribuição do passado, embora cada um realize essa tarefa [...] segundo seu temperamento e anseio cultural"4.

Ler atentamente documentos da vida privada, como cartas, ou recuperar crônicas dispersas do período, como aquelas publicadas no jornal A Província, em fase dirigida por Freyre ao lado de José Maria Bello, entre I928 e I930, oferece outras pistas para redimensionar o alcance das propostas estéticas e intelectuais do jovem sociólogo em período de plena efervescência artística e cultural. Aliás, o fundamental texto de Antonio Dimas sobre o "pantagruélico, rabelaisiano"s manifesto regionalista de I926, publicado em I952 e possivelmente reescrito - quiçá escrito - nessa ocasião, chama a atenção para a importância de se lerem outros documentos do período em que o projeto nascente de mergulho em "nosso éthos" fique mais patente, tais como a complexa e original produção registrada no Livro do Nordeste, Livro Comemorativo de I925, com interesses multidisciplinares de envergadura inovadora, publicado no centenário do Diário de Pernambuco. A década de 1920 constitui, de fato, um período rico em sugestões para esses escritores e artistas em estreito contato. $O$ próprio ensaísta, nesse polêmico Manifesto de I926, enfatiza, por exemplo, a relevância do jornal A Província, entre I928 e I930, como um: “[...] jornal em que se prolongou o Regionalismo do Congresso e do Centro Regionalista da Rua do Paissandu e no qual colaboraram os melhores escritores e artistas da região". A esses nomes, acrescentam-se ainda outros do Rio de Janeiro e de São Paulo, como Bandeira, Joanita Blank, Ribeiro Couto e o próprio Mário de Andrade, o que demonstra uma tentativa deliberada de construir - reforço aqui o caráter eminentemente narrativo e nada transparente dessa aventura intelectual - uma espécie de éthos da mistura e da fusão entre regional e nacional, tradição e modernidade: "Pois o Brasil é isto: combinação, fusão, mistura. E o Nordeste, talvez a principal bacia em que se vêm processando essas combinações, essa fusão, essa mistura de sangues e valores que ainda fervem”.

Em particular, a ação cultural de Freyre produz ressonâncias, de modo difuso, na trajetória intelectual de inúmeros escritores do período fora do eixo Rio-São Paulo, mais tarde reunidos sob a rubrica de Movimento do Nordeste, cujos principais representantes, segundo Otto Maria Carpeaux, teriam sido José Américo de Almeida, José Lins do Rego, Rachel de Queiroz, Amando Fontes, Graciliano Ramos e Jorge

4 SOUZA, Gilda de Mello e. A ideia e o figurado. São Paulo: Duas Cidades; Ed. 34, 2005, p. 5 I.

5 DIMAS, Antonio. Um manifesto guloso. Légua er meia: Revista de Literatura e Diversidade Cultural, ano 3, n. 2, 2004, p. 23.

6 Continua Freyre, em introdução não paginada ao manifesto: “Entre outros, José Américo de Almeida, Jorge de Lima, Pontes de Miranda, Luiz Jardim, José Lins do Rego, Barbosa Lima Sobrinho, Cícero Dias, Olívio Montenegro, Sívio Rabello, Rafael Xavier. 'A província' foi também jornal em que se estrearam jovens talentos da região, entre outros Nehemias Gueiros, José Antônio Gonçalves de Melo Neto e Mário Lins”. FREYRE, G. Manifesto regionalista de I926. Recife: Edições Região, I952.

7 Ibidem, p. 70. 
Amado, além do próprio sociólogo ${ }^{8}$. De fato, é possível encontrar análises de relativo fôlego que avaliam a presença de Freyre na literatura regionalista-modernista da década de I930, seja para reforçar encontros fecundos, seja - em outro extremo para destacar a idealização fundamentalmente acrítica da miséria e dos efeitos da exclusão social ou um pendor excessivamente nostálgico a prejudicar uma percepção lúcida e crítica de seu objeto -, o que demonstra quão díspar tem sido a recepção crítica de sua obra'. Nesse sentido, mostra-se relevante ler a obra de Freyre e de seus interlocutores pontuando convergências e divergências na condição processual desses discursos, bem como oferecendo visadas consequentes e polifônicas da dinâmica intelectual do período ${ }^{\text {Io }}$. Trata-se, portanto, de escrita plural, que se desenha no mesmo passo em que particulariza o "funcionamento peculiar do tempo brasileiro", captado em seu aspecto constelar, capaz de abalizar avanços e retrocessos, polirritmias, descompassos, anacronismos e acelerações vertiginosas em sua própria constituição - aproveito-me aqui das palavras de Ettore Finazzi-Agrò na leitura que faz da Formação da literatura brasileira, de Antonio Candido, as quais me parecem muito precisas também para caracterizar a escrita ensaística e plástica de Freyre nesse período ${ }^{\text {II }}$.

A divulgação recente de edições fidedignas de cartas e de estudos críticos sobre a epistolografia no Modernismo brasileiro vem, de modo paulatino, possibilitando situar a missiva, como objeto e como fonte, no centro de importantes debates. Além de colaborar para um enfoque sob o ponto de vista da "literariedade impura"ז2, cartas - uma forma indiscutivelmente híbrida - podem ser abordadas, por exemplo, sob vieses biográficos, testemunhais, memorialísticos ou documentar os bastidores da vida intelectual, literária e artística de determinado período. Contíguas ao conceito de "arquivo da criação", permitiriam mapear as diferentes etapas construtivas de uma

8 Cf. CARPEAUX, Otto Maria. Pequena bibliografia crítica da literatura brasileira. Rio de Janeiro: Ediouro, s.d.

9 Destaco, respectivamente nesses extremos, os seguintes trabalhos: CASTELO, José Aderaldo. José Lins do Rego: Modernismo e regionalismo. São Paulo: Edart, I96I; D’ANDREA, Moema Selma. A tradição re(des)coberta: Gilberto Freyre e a literatura regionalista. Campinas: Ed. da Unicamp, I992.

Io Infelizmente, nos dias de hoje, parece ainda difícil pontuar, em perspectiva analítica, a amplitude da ressonância que Freyre teve na vida intelectual brasileira ao longo do século XX. Antonio Candido, por exemplo, afirma, no ensaio “Raízes do Brasil”, prefácio à quinta edição do livro de Sérgio Buarque de Holanda, datado de I969, o impacto de Casa-grande er senzala (I933): “O jovem leitor de hoje talvez não possa compreender [...] a força revolucionária, o impacto libertador que teve esse grande livro. Inclusive pelo volume de informação, resultante da técnica expositiva, a cujo bombardeio as noções iam brotando como numa improvisação de talento, que coordenava os dados conforme pontos de vista totalmente novos no Brasil daquele tempo”. CANDIDO, Antonio. Raízes do Brasil. In: Teresina etc. Rio de Janeiro: Paz e Terra, I980, p. I36. Tempos depois, afirmaria em entrevista: “Quero dizer ainda que aos poucos fui vendo outros lados do livro, nem sempre favoráveis. Creio que o li inteiro umas cinco vezes, e uma coisa que acabou parecendo negativa foi a visão senhorial”. CANDIDO, Antonio. Entrevista com Antonio Candido. Revista Brasileira de Ciências Sociais, v. I6, n. 47, out. 200I, p. 7.

II FINAZZI-AGRÒ, Ettore. Entretempos. São Paulo: Editora Unesp, 2013.

I2

Cf. DIAS, Silvana Moreli Vicente. Cartas provincianas..., op. cit., p. 270-290. 
obra ${ }^{\mathrm{I} 3}$, o que poderíamos estender também para os projetos em ebulição nos anos mais combativos e experimentais da década de I920 no Brasil. No ensaio "A epistolografia como desafio à história e à teoria da literatura”, depois de constatada a importância de futuros estudos nessa área, João Cezar de Castro Rocha afirma: "Os 'estudos sobre cartas' deverão respeitar o caráter plural do objeto e, na medida do possível, apresentar uma análise de tipo fenomenológico da correspondência, atentando-se para as circunstâncias de sua produção e recepção" ${ }^{4}$. E, mais, considerando que "la sincérité de l'épistolier n'est qu'un mythe auquel d’aucuns se sont laissé prendre”, seria crucial ler a correspondência de escritores por meio de cuidadosas mediações, atentas para a historicidade e para a característica performática dos documentos da vida privada que acessamos, confrontando-os, quando possível, com outros documentos de época, com obras efetivamente publicadas em vida pelos autores e também com os projetos geracionais que circulavam no hic et nunc da enunciação - perspectiva essa que observa o texto para além de sua condição de fonte de sentidos acabados ou índices de outros textos estáveis. Levando em conta tais características que permeiam os estudos de correspondência, este artigo pretende destacar a importância de uma perspectiva multidisciplinar como pano de fundo para se perceberem os projetos em gestação em plena década de I920, o que prepara, de certo modo, o terreno para as conquistas formais e temáticas, no contexto do Movimento do Nordeste, que seriam consolidadas sobretudo na década de I930.

Nesse sentido, um dos procedimentos que recorrem nos escritos desse período é a tentativa de dar configuração literária a imagens relacionadas ao universo infantil. Os papéis desempenhados na infância em seu "minipalco", antes da cristalização do si mesmo arcaico, proporcionariam o entendimento de como os futuros papéis, com acertos e erros, viriam a ser representados pelo adulto no meio social ${ }^{16}$. Observe-se como a temática aparece em carta inédita de Gilberto Freyre a José Lins do Rego, datada de 27 de junho de I927 e enviada a propósito do recebimento dos originais de um poema de Jorge de Lima (I893-I953):

Recife, 27 de junho de I927.

Meu querido Lins:

Chegou-me anteontem sua nota, lembrando-me a carta que lhe devo. Já recebera os livros tão gentilmente enviados pelo seu amigo Dr. Jorge de Lima. Li o poema com

I3 Remeto aqui, em especial, ao artigo: MORAES, Marcos Antonio de. Epistolografia e crítica genética. Ciência e Cultura, São Paulo, v. 59, n. I, p. 30-32, jan.-mar. 2007.

I4 ROCHA, João Cezar de Castro. Exercícios críticos. Chapecó: Argos, 2008, p. I53.

I5 HAROCHE-BOUZINAC, Geneviève. L'épistolaire. Paris: Hachette Livre, I995, p. I3.

I6 Essa afirmação se baseia em Tzvetan Todorov, para quem, "em parte, nosso comportamento é o resultado de fatores múltiplos, passados e presentes; mas também, é preciso acrescentar, nosso comportamento ilustra o exercício de nossa liberdade e preserva, por esta razão, uma parte irredutível de mistério”. TODOROV, Tzvetan. A vida em comum. Ensaio de antropologia geral. Trad. Maria Angélica Deângeli e Norma Wimmer. São Paulo: Ed. Unesp, 20I4, p. I8I. 
interesse e simpatia - assunto é dos que mais me prendem como você sabe ${ }^{\mathrm{I} 7}$. Há umas coisas duras na linguagem, brigando com o assunto e com a intimidade do poema, como por exemplo: "o sol e as crianças vão deitar-se" quando "o sol e os meninos vão se deitar" ficaria cem vez mais próprio e interessante. A expressão "Mãe negra noite” é das mais felizes. (Por que as aspas em "Mãe negra” - não compreendo.) "E os sabugos de milho mugem como bois de verdade” é outra coisa deliciosamente feliz no poema. Há umas palavras elegantes demais para o ambiente de imaginação de menino que o poema procura criar. Por exemplo: galantear (o senhor D. Gallo deixa de galantear). Mas a verdade é que, no conjunto, o poema é (no assunto) das coisas mais doces que tenho lido em português - tão tristemente pobre nestas coisas; e fico contente de possuir um exemplar - eu que ultimamente venho antes encontrando alegria em me desfazer de livros do que em adquiri-los. O romance, lidas as primeiras páginas, e um bocado aqui, outro adiante - francamente, não tive coragem de ler; não sei se o título, ou o que, fez que se engraçasse dele o Dr. Germano Guimarães, que me pediu p'ra levar, e eu dei; você não fique zangado com isso; você sabe que eu sou assim mesmo[... $]^{18}$.

O ano de I927 marca o rompimento de Jorge de Lima com o parnasianismo. Por intermédio de José Lins do Rego, percebemos que o poeta enviou a Freyre, naquela ocasião, dois livros. Um deles seria $O$ mundo do menino impossível, ao que tudo indica, em edição artesanal, publicado com tiragem de 300 exemplares ilustrados pelo autor e coloridos por seu irmão, Hildebrando de Lima. A carta de Gilberto Freyre enviada a José Lins do Rego indica como o sociólogo atuava animando os "provincianos"

I7 Gilberto Freyre se refere ao poema que compõe o livro de Jorge de Lima intitulado O mundo do menino impossível, transcrito a seguir na íntegra: "Lusco-fusco./ As primeiras estrelas/ vêm ouvir/ os derradeiros sinos// As velhas luas/ vêm chorar/ com os últimos poetas...// Os ninhos vão dormir/ Os pintinhos vão sonhar/ O senhor D. Gallo/ deixa de galantear.// E as duas únicas/ cousas novas deste mundo:/ o sol e as crianças,/ vão deitar-se.// Mas ainda vela/ o menino impossível/ ali do lado/ enquanto todas as crianças/ mansas/ dormem,/ acariciadas/ por 'Mãe-Negra' Noite.// O menino impossível/ que destruiu/ os brinquedos perfeitos/ que os vovôs lhe deram:// O urso de Nurenberg,/ O velho barbado yugo-eslavo,/ As poupées de Paris aux cheveux crêpes,// O carrinho português feito de/ folha de Flandres,/ A caixa de música checo - eslovaca,/ O polichinello italiano,/ made na Inglaterra,// O trem de ferro de U.S.A./ e o macaco brasileiro/ de Buenos Ayres/ moviendo la cola y la cabeza;// O menino impossível/ que destruiu até/ os soldados de chumbo/ de Moscou/ e furou os olhos de um 'Papá Noel',/ brinca com sabugos de milho,/ caixas vazias,/ tacos de pau,/ pedrinhas brancas do rio...// 'Faz de conta que os sabugos/ são bois...'/ 'Faz de conta...'/'Faz de conta...'// E os sabugos de milho/ mugem como bois de verdade...// E os tacos que deveriam ser/ soldadinhos de chumbo são/ cangaceiros de chapéu de couro...// E as pedrinhas balem!// Coitadinhas das ovelhas mansas/longe das mães,/ presas nos curraes de papelão!// Faz lusco-fusco/ no mundo que o menino impossível/ povoou sosinho!//É tão tarde!// A mamãe cochila./ O papai cabecêa./ O relógio badala.// E vem descendo/ uma noite encantada/ da lâmpada que expira/ lentamente/ na parede da sala...// O menino poisa a testa e sonha/ dentro da noite quieta/ da lâmpada apagada/ com o mundo maravilhoso/ que ele tirou do nada...// Chô! Chô! Pavão!”. LIMA, J. de. O mundo do menino impossível. Ilustrado pelo Autor. Colorido por Hildebrando de Lima. Rio de Janeiro: Typographia, I927. Foi mantida a grafia original.

I8 Carta inédita de Gilberto Freyre e José Lins do Rego, com datação “Recife, 27 de junho de I927”. Original sob a guarda do acervo do Museu José Lins do Rego. Funesp-PB. 
a se expressarem com autenticidade ao: sugerir expressões mais características de variantes do português falado no Brasil, que tende, por exemplo, à próclise ao invés da ênclise; e destacar, ainda, a importância de uma seleção lexical típica da oralidade. Freyre, portanto, demonstra uma consciência precursora acerca da linguagem a destacar aspectos estruturais das variedades faladas do português brasileiro que seriam, somente décadas depois, objeto de pesquisa sistemática. Nesse sentido, busca uma aderência ao universo popular por meio da linguagem artisticamente trabalhada, destacando a importância de se lastrear a imagética do universo infantil na experiência cotidiana. Propõe, portanto, que a linguagem se dispa das perspectivas idealizadas, lusitanas e elitistas de modo a aproximarem-se língua falada e língua escrita. É certo que a sociedade hoje pode ver com naturalidade proposições como essa - muito embora, em termos linguísticos, permaneçamos, em geral, extremamente conservadores; entretanto, à época, questionar princípios da norma padrão, sobretudo no Brasil de história colonial e escravocrata, funcionava como energia transgressora e modernizadora indiscutível ${ }^{\text {I9. }}$. Mais ainda, Freyre percebe nessa questão uma potência estética: quando afirma a atmosfera da "imaginação do menino" e a "intimidade do poema", chama a atenção para a autonomia do texto que permite engendrar um mundo singular, em que o poético é regulado por uma economia própria, em busca da surpresa e do "autêntico" da experiência.

Ao revisitar a infância e ter diante dela uma perspectiva "autêntica”, na linha do que afirma Ricardo Benzaquen de Araújo sobre Freyre, se criaria a impressão de que as "afirmações se referem a uma verdade absolutamente pessoal e incontrolável, próxima daquela que é sustentada nas confissões e nas autobiografias, posto que fruto de seu 'pertencimento' à própria sociedade que está examinando”2o. Aproxima-se, assim, da expressão "autêntica” e do ímpeto provinciano, que pode lançar mão inclusive das máscaras, da ironia e da violência para dar sentido pleno ao seu relato. Como afirmou Lionel Trilling em Sinceridade er autenticidade, a etimologia da palavra "autêntico" remete ao grego authentes: não somente senhor

I9 O caráter ideológico da normatização linguística tem sido bem demonstrado, em tempos atuais e com consistente embasamento teórico, por linguistas como Carlos Alberto Faraco, Dante Lucchesi e Marcos Bagno. Contudo surpreende como esse debate ainda está longe de um consenso mínimo mesmo no campo acadêmico, o que nos permite constatar que pensadores como Freyre e outros modernistas tocaram de leve questões centrais que não foram posteriormente desenvolvidas em profundidade a ponto de desmontar os mitos conectados à normatização linguística no Brasil. Segundo Lucchesi: “[...] a Linguística talvez seja a ciência que menos dialoga com a sociedade. Para romper esse isolamento - e superar as forças sociais às quais esse isolamento interessa -, os linguistas terão que promover essa interação entre as questões que dizem respeito ao conhecimento científico da língua e questões da língua que hoje dizem respeito à sociedade”. LUCCHESI, Dante. Língua e sociedade partida: a polarização sociolinguística do Brasil. São Paulo: Contexto, 20I5, p. 304. Essa interação foi precisamente intuída por alguns de nossos escritores modernistas, como podemos ver neste ensaio.

20 ARAÚJO, Ricardo Benzaquen de, op. cit., p. I86. 
absoluto e fazedor, mas também destruidor, perpetrador, assassino, suicida ${ }^{2 \mathrm{~T}}$. O cerne da autenticidade abarca, portanto, sentidos contraditórios e até aporéticos, muito distantes de qualquer idealização, complacência ou nostalgia acrítica. Portanto, os pendores autobiográfico e biográfico - percorridos e defendidos inclusive em escritos da vida privada, como cartas - concorreriam para se construir uma atmosfera de autenticidade, de equilíbrio discursivo delicado, contraditório e precário, atenta aos - mas não protegida dos - perigos da estilização, da estereotipia e das tautológicas repetições, como veríamos nos escritos de Freyre sobretudo após a década de $194 \mathrm{O}^{22}$. O autor não estaria, portanto, imune a uma visão interpretativa ideológica, narcísica e, nesse sentido, parcial, mas também não se furtaria aos incômodos, às culpabilidades, aos constrangimentos e às violências - assim como aos prazeres sadomasoquistas perpetrados por actantes da sociedade em que está inserido.

Mais ainda, é revelador descobrir que o próprio Freyre, enquanto estimulava essa visão da infância como voz poética potente em um Jorge de Lima, gestava, ele mesmo, uma obra centrada na vida de menino no Brasil em fins da década de I920, o que lembra ainda outras obras seminais como Menino de engenho ${ }^{23}$, que seria publicado em 1932 por José Lins do Rego, um de seus interlocutores mais próximos. Leia-se carta enviada por Freyre a Manuel Bandeira com datação "Recife, 6 de maio de I929":

Recife, 6 de maio de I929.

Meu caro Baby Flag:

Vai esta com a nota de confidential porque é assunto que desejo fique encoberto dos literatos. Agora que estou ganhando um pouco mais (embora reunindo responsabilidades e deveres de três indivíduos) estou empregando as economias na compra de livros referentes à vida íntima do Brasil (muitos deles só de passagem), a estudos sociais, em geral, sobre a família e especialmente sobre a vida e a história da criança, em vários países e em diferentes condições de cultura. Já estou com um bom começo de biblioteca especializada e outros desses livros me estão a chegar. Esse trabalho e essa reunião de livros - como vocêé um dos raros a saber - prende-se a um estudo,

2I "Os procedimentos do grande movimento artístico do início do século podem servir para nos conscientizar dos violentos sentidos que a origem grega da palavra 'autêntico' explicita. Authenteo: ter pleno poder sobre, cometer assassinato. Authentes: não somente senhor absoluto e fazedor, mas também perpetrador, assassino e suicida”. TRILLING, Lionel. Sinceridade e autenticidade. A vida em sociedade e a afirmação do eu. Tradução de Hugo Langone. São Paulo: É Realizações Ed., 20I4, p. I47.

22 Ricardo Benzaquen de Araújo, em seu incontornável Guerra e paz, conclui seu livro destacando a necessidade de se aprofundarem os estudos de Freyre pela trilha do ensaísmo de natureza autobiográfica. Dá a entender, nesse sentido, que da fraqueza do relato como documento nasce sua riqueza como escrita literária e testemunho. ARAÚJO, Ricardo Benzaquen de, op. cit. Seria, portanto, desejável que se ampliassem os estudos sobre os textos memorialísticos do sociólogo e-como desenvolvo aqui - os meandros da interlocução do autor com sua geração. Ainda, para quem busca considerações bastante pertinentes sobre o caráter autoinventivo dos textos de Freyre, deve-se conferir, desde a introdução: PALLARES-BURKE, Maria Lúcia Garcia, op. cit.

23 REGO, José Lins. Menino de engenho. 74. ed. Rio de Janeiro: José Olympio, I999. 
sob o ponto de vista psicológico e histórico, que há anos me prende, e adiado pela falta absoluta de entusiasmo e falta de recursos de estudo e leitura aqui. Sucede que apareceu uma fagulhazinha de entusiasmo e, em vez do miserável dinheiro que me trazia sempre em dívidas, estou ganhando (embora com sacrifício de conforto e saúde) o bastante para me dar ao luxo de adquirir livros sobre um estudo especializado como o que me vem há tempos ocupando a um estudo da vida de menino no Brasil. Esse estudo teria de começar pela vida de menino entre os nossos índios. Aqui vocême pode ajudar no seguinte: na parte referente às cantigas de ninar meninos entre os índios; cantigas de brinquedos infantis entre eles; sobrevivência no moderno canto infantil brasileiro dessas influências. Roquette-Pinto fala um pouco - muito pouco - do assunto em Rondônia. Você não podia ver se ele tem outros estudos no assunto? E se no Museu Nacional não há mais a respeito? Tudo isso muito discretamente. Também se no Museu não há bonecas de palha ou outros brinquedos índios que pudessem ser fotografados. $\mathrm{E}$ livros alemães de etnografia sobre o Brasil - não há na Biblioteca Nacional? Seu Baby Flag, vamos ver se você se toma de interesse pelo assunto. Estou reunindo material. Toda a minha economia é para isso. (É claro que ninguém por fora sabe). Bigodão já acha demais tanto livro caro. Mas o assunto é fascinante. [... $]^{24}$.

E, voltando um pouco no tempo, é possível flagrar outras conexões entre o ensaísta pernambucano e a poesia moderna brasileira: por exemplo, Jorge de Lima teria escrito seu primeiro poema modernista sob influxo de um outro poema modernista, "Evocação do Recife”, de Bandeira, feito a pedido de Freyre, em carta, para figurar na edição comemorativa do Livro do Nordeste, concebido com viés multidisciplinar e organizado pelo ensaísta por ocasião do centenário do periódico pernambucano. Quem testemunhou a gênese da modernização poética de Jorge de Lima foi o próprio Lins:

Manuel Bandeira é culpado em muito desses poemas do jovem poeta de Alagoas.

O caso do príncipe dos poetas alagoanos foi muito simples. Foi uma conversão como a do drama de H. Ghéon: o autor Genest que se converteu representando a vida de $S$. Adriano. Um dia Jorge de Lima leu a “Evocação do Recife”, de Manuel Bandeira. E quis fazer uma pilhéria com o belo poema de Bandeira. Quando terminou, não era mais o príncipe Jorge de Lima, era apenas um poeta. A brincadeira custara-lhe a coroa que lhe dera "O acendedor de lampiões", o seu soneto de dó de peito, para quem Osório Duque Estrada andou marcando lugar nas antologias ${ }^{25}$.

Por trás dessa “inflexão provinciana” na literatura brasileira está Gilberto Freyre, como uma espécie de maestro invisível, buscando um tônus diferenciado à expressão poética que escava a memória para compor a história, com suas arestas e contradições e sempre com um interesse multidisciplinar, que se tornaria característico em sua

24 DIAS, Silvana Moreli Vicente. Cartas provincianas..., op. cit., p. 40-4I.

25 REGO, José Lins. Jorge de Lima e o modernismo. In: . Dias idos e vividos. Rio de Janeiro: Nova Fronteira, I98I, p. 53. 
extensa obra. A infância que se desenha no contexto do patriarcalismo é, por exemplo, aquecida e mesmo resguardada pela afetividade que exala da senzala silenciada. Sendo mágica, essa meninice é refratária às mercadorias produzidas no contexto do capitalismo, como se antevê no "Mundo do menino impossível”, de Jorge de Lima. Na "Evocação do Recife" de Manuel Bandeira, a infância permite, dentre outras leituras, compor uma crônica da vida urbana nascente permeada por signos da vida rural. $\mathrm{O}$ sentimento com relação ao passado parece pendular, oscilando ora à nostalgia ora à melancolia, transmitido pela atmosfera elegíaca que se delineia pela repetição da imagem do "avô morto" e do "Recife morto", em outras palavras, da própria infância morta, recriada poeticamente, construindo alianças entre a memória e a história, entre a linguagem e a vida:

\author{
Recife... \\ Rua da União... \\ A casa de meu avô... \\ Nunca pensei que ela acabasse! \\ Tudo lá parecia impregnado de eternidade \\ Recife... \\ Meu avô morto. \\ Recife morto, Recife bom, Recife brasileiro como a casa de meu avô ${ }^{26}$.
}

Entretanto, na infância também atua a força repressora e da hybris (excesso e arrogância) que deforma personalidades em vias de formação, como se percebe pelo fechamento de Menino de engenho, de José Lins: “Eu não sabia nada. Levava para o colégio um corpo sacudido pelas paixões de homem feito e uma alma mais velha do que o meu corpo. [...] Eu não: era sabendo de tudo, era adiantado nos anos, que ia atravessar as portas do meu colégio./ Menino perdido, menino de engenho"27.

Nesse contexto, a infância não é somente um tema com múltiplas reverberações: constitui uma espécie de energia visceral, uma porta de entrada para um universo múltiplo, rico, escorregadio às lentes burguesas que teriam tomado de assalto o Brasil sobretudo após a transferência da corte portuguesa ao país em I808, caracterizando o início de um período de embate de forças tensivas, polarizadas entre a tradição patriarcal e a ocidentalização individualizante ${ }^{28}$. Nuances de tempos descontínuos seriam captadas em especial por meio de topoi como a infância, que facilitam a apreensão da pluralidade da linguagem e da sociabilidade que se constrói no país em acelerado processo de modernização, palco de uma confluência peculiar de forças contraditórias, em vias de intensa urbanização e diferenciação social. Nesse sentido, não admira que o ímpeto pela reconstrução da memória familiar se manifeste no diálogo dos missivistas que se dedicam à reconstrução do universo da criança, como notamos na carta enviada por Freyre a Lins por ocasião da morte do avô de José Lins, José Lins Cavalcanti de Albuquerque, com datação “Sexta-feira, 29 de maio de I924”:

\footnotetext{
26 BANDEIRA, Manuel. Poesia completa e prosa. Rio de Janeiro: Nova Aguilar, I974, p. 2I4.

27 REGO, José Lins. do. Menino de engenh, op. cit., p. 82.

Cf. FREYRE, Gilberto. Sobrados e mucambos. I4. ed. São Paulo: Editora Global, 2003.
} 
Meu caro:

Acabo de receber sua carta: li-a com ansiosa delícia. Já não compreendia seu silêncio - sabendo-o o amigo cheio de ternura que é, que tem sido há um ano; e cuja amizade eu muito prezo.

Boa figura de senhor de engenho deve ter sido aquele seu avô. Eu não sei qual é o gosto de ter um avô: o materno já era morto quando eu nasci e o paterno morreu quando eu era muito pequeno. O último morreu senhor de engenho. Só tenho recordações da minha avó materna. Tinha oito ou nove anos quando ela morreu e chorei muito. Gostava muito dela. Fui muitas vezes à missa na sua companhia: ela queria que eu fosse ser padre - talvez o meu verdadeiro destino. Não sei. É difícil dizer [... $]^{29}$.

É possível observar como essa carta alinhava questões prementes da trajetória de Gilberto Freyre e José Lins do Rego. As relações pessoais - sobretudo os laços de família vistos sob o prisma da infância - ocupam lugar de destaque para propiciar o suporte afetivo e intelectual dos escritores que aos poucos delineiam seus projetos de escrita desde a província. Mesmo quando a infância não é particularmente referenciada, ainda assim é indiretamente revisitada pelo esboço da convivência com os avós. A ocasião em que a carta foi escrita é bastante precisa: é o primeiro documento de Freyre enviado a José Lins após a morte do avô deste. Nascido em 3 de junho de I90I, no Engenho Tapuá, em São Miguel de Taipu, Paraíba, sendo seus pais João do Rego Cavalcanti Sobrinho e Amélia Lins Cavalcanti de Albuquerque, cedo José Lins foi mandado para a casa do seu avô materno, José Lins Cavalcanti de Albuquerque, após a morte prematura da mãe. Na apresentação a seu livro de memórias Meus verdes anos, de I956, afirmou:

A vida idílica se desviava em caminhos espinhentos. O neto de um homem rico tinha inveja dos moleques da bagaceira. A separação violenta de minha segunda mãe marcou-me a sensibilidade de complexo de renegado. A ausência do pai que não era bem visto pelos parentes maternos fez de mim uma criatura sem verdadeiro lastro doméstico. Sempre fui um menino criado pelo avô, assim como um enjeitado, apesar de todas as grandezas do avô ${ }^{30}$.

E, mais adiante, no livro de I956, analisou essa figura modelar em seu processo de individuação e autoconhecimento:

29 Gilberto Freyre dedicou seu primeiro livro, Casa-grande e senzala, aos seus avós: "à memória dos meus avós/ Francisca da Cunha Teixeira de Mello/ Alfredo Alves da Silva Freire/ Maria Raymunda da Rocha Wanderley/ Ulysses Pernambucano de Mello". FREYRE, G. Casa-grande e’senzala. 37. ed. Rio de Janeiro: Record, I999.

30 REGO, José Lins. Meus verdes anos: memórias. Rio de Janeiro: José Olympio, I997, p. 3. 
Olhava eu o meu avô como se fosse o engenho. A minha grandeza da terra era a sua grandeza. Fixara-se em mim a certeza de que o mundo inteiro estava ali dentro. Não podia haver nada que não fosse do meu avô. Lá ia o gado para o pastoreador, e era dele; lá saíam os carros de boi a gemer pela estrada ao peso das sacas de lã ou dos sacos de açúcar, e tudo era dele; lá estavam as negras da cozinha, os moleques da estrebaria, os trabalhadores do eito, e tudo era dele. O sol nascia, as águas do céu se derramavam na terra, o rio corria, e tudo era dele. Sim, tudo era do meu avô, o velho Bubu, de corpo alto, de barbas, de olhos miúdos, de cacete na mão. O seu grito estrondava até os confins, os cabras do eito lhe tiravam o chapéu, o dr. José Maria mandava buscar lenha para a sua cozinha no Corredor, e a água boa e doce nas suas vertentes. Tudo era do meu avô Bubu, o Velho da boca dos trabalhadores, o Cazuza da velha Janoca, o papai da tia Maria, o meu pai da tia Iaiá ${ }^{31}$.

Meus verdes anos, livro de memórias tardio de José Lins, aborda a infância do escritor e demonstra claramente como o avô materno foi figura inspiradora para que se delineasse o perfil do avô de Carlinhos, José Paulino, de Menino de engenho, de I932, livro, por sua vez, de pendor mais ficcional. As convergências são muitas, de modo que Menino de engenho desponta como uma espécie de "autoficção" avant la lettre, antecipando (apesar da ausência de patente ou clara identidade onomástica entre autor, narrador e protagonista, típica desse gênero pós-moderno) o pendor autobiográfico que seria mais fortemente desenvolvido na contemporaneidade ${ }^{32}$. De qualquer modo, a construção do personagem do avô não só reverbera na trama narrativa, na sequência dos acontecimentos, mas fornece também uma matriz narrativa ${ }^{33} \mathrm{com}$ a qual o narrador híbrido, que tateia a verdade no movediço terreno entre o histórico e o ficcional, pode fazer escolhas esteticamente verossímeis para representar o complexo universo patriarcal, contrabalançado problematicamente entre intimidade e autoritarismo. A vida da criança equilibra-se entre o idílico e o espinhoso, precariedade que é recriada ficcionalmente já no livro de estreia do autor.

Desse modo, a infância revela-se como uma construção literária tensiva, que oscila entre a nostalgia e a melancolia, o épico e o trágico, a história e o mito. Ela mesma é um tema que revela poder estruturador ao alinhavar, de modo

3I Ibidem, p. 2I.

32 O termo foi empregado por Serge Doubrovsky em I977 para descrever as narrativas em que há identidade onomástica entre autor, narrador e protagonista. Segundo afirma Doubrovsky, o livro Fils, de I977, foi escrito em resposta à "casa cega" presente no quadro produzido por Philippe Lejeune em O pacto biográfico (1975). Esse espaço abrangeria a existência da homonímia e a forma ficcional, estilhaçando o conceito de autenticidade como contíguo à introspecção sincera, rigorosamente autobiográfica. DOUBROVSKY, Serge. Fills. Paris: Galilée, I977.

33 Para Luís Bueno, ao lado da velha Totonha, o avô constitui um modelo de narrador que já "caminha em direção ao mundo letrado. Embora também orais, as histórias do avô, sempre tratando do passado da família, são obra 'de cronista'. [...] A realidade que o cronista pode imprimir a sua história, porém, não vem da estreiteza dos horizontes [...] mas de um alargamento de perspectiva que é capaz de localizar a grandeza dos valores familiares no corpo geral da história do país”. BUENO, Luís. Uma história do romance de 30. São Paulo: Edusp; Campinas: Ed. Unicamp, 2006, p. I54). 
problemático, disposição afetiva e disposição intelectual, popular e erudito. Ãquela época, indiscutivelmente sua evocação, ao lado da evocação da província, trazia possibilidades literárias praticamente inexploradas na literatura brasileira; sua plausibilidade era, outrossim, buscada sobretudo em dados concretos da experiência e do cotidiano. O papel de mediação de Gilberto Freyre se revela na consistência de suas proposições e estímulos difundidos entre colegas e amigos. Foi assim que pediu o poema "Evocação do Recife" a Manuel Bandeira, que figurou na edição comemorativa do Livro do Nordeste com destaque. Aliás, esse foi um momento de verdadeira inflexão poética rumo à província natal, mediada pelo olhar infantil, como se procurou articular no livro Cartas provincianas ${ }^{34}$.Porém, para se compreenderem as especificidades ambíguas desse dinâmica da vida de criança que se mistura com o "éthos da província", seria crucial constituir, especificamente, um lugar entredisciplinar ${ }^{35}$, espaço de intercâmbio, negociação, fluxo, largo espectro que não se identifica nem com a "nostalgia da origem", nem com a "teleologia utópica", embora com elas possa se relacionar de forma tensiva, ora tendendo aos discursos sobre a formação da nacionalidade brasileira - os quais têm, obviamente, uma indelével marca construtiva -, ora buscando dialogar com a ruptura vanguardista, ousadia pendular que vemos, de modo bem marcado, no poema "Evocação do Recife", de Manuel Bandeira.

Assim, quando Freyre e seus amigos procuram delimitar o que se denomina "éthos da província”, normalmente o relacionam a aspectos fugidios do passado que teriam deixado uma inapagável marca no presente. Notamos em crônica de Manuel Bandeira inédita em livro, publicada em A Província, na edição comemorativa pelos dois anos do jornal, no dia 28 de setembro de I930 - portanto, às vésperas da revolução de I930 (iniciada em 3 de outubro) e do consequente exílio de Freyre na Bahia, Portugal e depois Estados Unidos -, o esforço no sentido de se construírem identidades formais misturadas. Leia-se a seguinte passagem:

Passei o dia de hoje mergulhado na leitura do número do segundo aniversário da última fase de A Província. Foi como uma evasão para a longínqua província querida. O tempo favorecia-a, com um desses dias de chuva peneirada em que faz frio até o mais fundo do coração. Santa Teresa estava toda sitiada de névoas espessas, de sorte que eu me sentia bem confinado no meu quarto. E o meu quarto era Pernambuco, pelo sortilégio afetuoso dos bons amigos de A Província.

34 DIAS, Silvana Moreli Vicente. Cartas provincianas..., op. cit.

35 Tomo emprestado um termo que foi empregado por Marcos Siscar ao refletir sobre a poesia moderna e contemporânea e o discurso literário da crise: "Designar a literatura com lugar, usá-la inclusive como designação de um determinado interesse sobre as relações de troca, nos levaria a constituir um lugar da enunciação - que eu chamaria entredisciplinar - a partir do qual fosse possível compreender inclusive a lógica dos outros discursos (sociais, científicos, religiosos) com o auxílio dos instrumentos que a convenção ou a tradição literária traz em sua esteira (análise da linguagem, ênfase nas aporias, estratégias de formulação do conhecimento)". SISCAR, Marcos. Poesia e crise: ensaios sobre a "crise da poesia" como topos da modernidade. Campinas/SP: Editora da Unicamp, 20Io, p. 40. 
Logo nas primeiras palavras de editorial vinha lembrado o meu nome a propósito do conceito provinciano de jornalismo. A Província nestes dois anos soube honrar incessantemente aquele conceito. De ordinário sob provincianismo se entende somente as ingênuas fraquezas dos meios pequenos. Esquecem-lhes todos as genuínas excelências. Ora o atual diretor de A Província, que é bom conhecido pelo seu gosto das coisas simples e genuínas, conseguiu na esfera do jornalismo ilustrar o melhor sentido da palavra. Não estandardizou o jornal à americana. Antes timbrou em relacioná-lo sempre aos recursos, às necessidades e às aspirações da vida pernambucana. [...]

A direção de A Província fala constantemente na sua pobreza. É na verdade pobreza de casa nobre, que enche de orgulho o coração dos amigos que a frequentam. [...]

Há quem pense que só os jornais agitados, gritadores, escandalosos possam assumir personalidade atraente. [...] Todos os camelots se parecem. Mas o sujeito inteligente e bem educado da província que a gente um dia encontra na Avenida Rio Branco, sujeito que viveu em Nova York, conhece Londres e Paris, mora no Recife sem falar em nada disso, trabalha no Recife, gosta do Recife, se interessa pelo Recife... É a impressão de um sujeito assim que me dá um jornal como A Província, que Deus conserve na sua cor atual ${ }^{36}$.

Esse seria uma espécie de éthos que reforça o equilíbrio entre experiências contrastantes, sentido esse que Bandeira sugere ao relacionar a impressão do modesto sujeito cosmopolita que se enraíza na província, o que lembra a trajetória do amigo e então editor Freyre. Essa leitura seria comunicada a vários intelectuais da época, amigos próximos e distantes, transmitindo uma ideia de atmosfera em ebulição, do ponto de vista tanto estético quanto ideológico, a partir da qual livros como Casa-grande er senzala (Freyre, I933), Menino de engenho (Lins, I932) e Libertinagem (Bandeira, I930) - que revisitam, cada qual a seu modo, a formação do ser individual, sua relação com a sociedade e a complexa constituição de um povo -, por exemplo, tomariam corpo.

Portanto, Freyre se tornou referência para uma geração de artistas e intelectuais que se lançaram a uma pesquisa deliberada por índices da nacionalidade que pudessem ser considerados verossímeis, autênticos e representativos para pessoas oriundas de um largo espectro social, político e cultural. Só para citar um dos novos núcleos de sociabilidade dos anos I930, a editora José Olympio torna-se centro de reunião para vários expoentes do Nordeste, e seu cuidadoso trabalho editorial passa a ser símbolo do novo espaço de agregação e de efervescência intelectual que consagraria vários desses novos escritores, representando bem o ímpeto desbravador

36 BANDEIRA, Manuel. Em louvor de um jornal provinciano. A Província, n. 225, 28 de setembro de I930, p. 3. Disponível em: 〈http://memoria.bn.br/DocReader/DocReader.aspx?bib=I28066_02\&PagFis=27I32〉. Acesso em: 28 jul. 2017 . 
daqueles tempos ${ }^{37}$. Nesse sentido, o tema da infância e correlatos como a província e a família ocupam um lugar de destaque no sentido de organizarem as experiências estéticas e históricas conduzidas por sujeitos que impulsionam os debates públicos - em um viés claramente multidisciplinar - lastreados desde o Nordeste brasileiro, em um primeiro momento, mas que posteriormente reverberam em todo o país, sobretudo após a Revolução de I930.

\section{SOBRE A AUTORA}

SILVANA MORELI VICENTE DIAS é pós-doutora pelo IEB/USP, pela Université Sorbonne Nouvelle Paris 3 e pela Università degli Studi di Roma "La Sapienza" e professora da Universidade Veiga de Almeida (UVA). E-mail: silvana.dias@uva.br.

\section{REFERÊNCIAS BIBLIOGRÁFICAS}

ARAÚJO, Ricardo Benzaquen de. Guerra e paz. São Paulo: Ed. 34, I994.

ARRUDA, Maria Arminda do Nascimento. Modernismo e regionalismo no Brasil: entre inovação e tradi-

ção. Tempo Social, Revista de Sociologia da USP, v. 23, n. 2, p. I9I-2I2, nov. 20 II.

BANDEIRA, Manuel. Poesia completa e prosa. Rio de Janeiro: Nova Aguilar, I974.

BASTOS, Elide Rugai As criaturas de Prometeu: Gilberto Freyre e a formação da sociedade brasileira. São

Paulo: Global/Fundação Gilberto Freyre, 2006.

BUENO, Luís. Uma história do romance de 30. São Paulo: Edusp; Campinas: Ed. Unicamp, 2006.

CANDIDO, Antonio. Gilberto Freyre crítico literário. In: AMADO, G. et al. Gilberto Freyre: sua ciência, sua filosofia, sua arte. Rio de Janeiro: J. Olympio, I962. . Raízes do Brasil. In: . Teresina etc. Rio de Janeiro: Paz e Terra, I980.

. Entrevista com Antonio Candido. Revista Brasileira de Ciências Sociais, São Paulo, v. 16, n. 47, p. 5-30, out. 200I.

CARPEAUX, Otto Maria. Pequena bibliografia crítica da literatura brasileira. Rio de Janeiro: Ediouro, s.d. CASTELO, José Aderaldo. José Lins do Rego: Modernismo e regionalismo. São Paulo: Edart,I96I.

D'ANDREA, Moema Selma. A tradição re(des)coberta: Gilberto Freyre e a literatura regionalista. Campinas:

Ed. da Unicamp, I992.

37 Segundo Maria Arminda do Nascimento Arruda, "Dessa forma, o chamado romance regionalista ganhou expressão pública com a aposta de José Olympio na nova geração, acrescida da promoção de José Lins do Rego, o primeiro a virar autor da instituição, por ele denominada de 'casa”. ARRUDA, Maria Arminda do Nascimento. Modernismo e regionalismo no Brasil: entre inovação e tradição. Tempo social, Revista de Sociologia da USP, v. 23, n. 2, p. I9I-2I2, nov. 20 II. 
DIAS, Silvana Moreli Vicente. Perfis da província e máscaras da modernidade: uma leitura da correspondência de Gilberto Freyre com Manuel Bandeira, José Lins do Rego e Rodrigo Melo Franco de Andrade. Letras de Hoje, n. 49, n. 2, 20I4.

. Cartas provincianas: correspondência entre Gilberto Freyre e Manuel Bandeira. São Paulo: Global, 2017.

DIMAS, Antonio Um manifesto guloso. Légua er meia: Revista de Literatura e Diversidade Cultural, ano 3, n. 2, 2004.

DOUBROVSKY, Serge. Fils. Paris: Galilée, I977.

FINAZZI-AGRÒ, Ettore. Entretempos. São Paulo : Editora Unesp, 2013.

FREYRE, Gilberto. Manifesto regionalista de I926. Recife: Edições Região, I952.

. Casa-grande er senzala. 37. ed. Rio de Janeiro: Record, I999.

. Sobrados e mucambos. I4.ed. São Paulo: Editora Global, 2003.

FREYRE, Gilberto et al. Livro do Nordeste. Introdução de Mauro Mota e prefácio de Gilberto Freyre. 2. ed. Recife: Arquivo Público Estadual, I979. Edição Comemorativa do primeiro centenário do Diário de Pernambuco. Edição fac-similar ao original de I925.

HAROCHE-BOUZINAC, Geneviève. L'épistolaire. Paris: Hachette Livre, I995.

LEJEUNE, Philippe. O pacto autobiográfico: de Rousseau à internet. Org. Jovita M. G. Noronha; trad. Jovita M. G. Noronha e Maria I. C. Guedes. Belo Horizonte: UFMG, 2008.

LIMA, Jorge de. O mundo do menino impossível. Ilustrado pelo autor. Colorido por Hildebrando de Lima. Rio de Janeiro: Typographia, I927.

LIMA, Luiz Costa. A versão solar do patriarcalismo: Casa-grande \& Senzala. In: A aguarrás do tempo: estudos sobre a narrativa. Rio de Janeiro: Rocco, I989.

LUCCHESI, Dante. Língua e sociedade partida: a polarização sociolinguística do Brasil. São Paulo: Contexto, 2015 .

MORAES, Marcos Antonio de. Epistolografia e crítica genética. Ciência e cultura, São Paulo, v. 59, n. I, p. 30-32, jan.-mar. 2007.

OLIVEIRA, Lucia Lippi. Gilberto Freyre e a valorização da província. Sociedade e Estado, v. 26, n. I, Brasília, jan.-abr. $20 I I$.

PALLARES-BURKE, Maria Lúcia. Gilberto Freyre: um vitoriano dos trópicos. São Paulo: Ed. Unesp, 2005. REGO, José Lins. Jorge de Lima e o modernismo. In: . Dias idos e vividos. Rio de Janeiro: Nova Fronteira, I98I.

. Meus verdes anos: memórias. Rio de Janeiro: José Olympio, I997.

. Menino de engenho. 74. ed. Rio de Janeiro: José Olympio, I999.

ROCHA, João Cezar de Castro. Exercícios críticos. Chapecó: Argos, 2008.

SISCAR, Marcos. Poesia e crise: ensaios sobre a "crise da poesia" como topos da modernidade. Campinas: Editora da Unicamp, 2010.

SOUZA, Gilda de Mello e. A ideia e o figurado. São Paulo: Duas Cidades; Ed. 34, 2005.

TODOROV, Tzvetan. A vida em comum. Ensaio de antropologia geral. Trad. Maria Angélica Deângeli e Norma Wimmer. São Paulo: Ed. Unesp, 20I4.

TRILLING, Lionel. Sinceridade er autenticidade. A vida em sociedade e a afirmação do eu. Tradução de Hugo Langone. São Paulo: É Realizações Ed., 20I4. 